\title{
ORDINARY INNOVATION OF MOBILE SERVICES
}

\author{
Steinar Kristoffersen \\ Petter Nielsen \\ Jennifer Blechar \\ Ole Hanseth \\ University of Oslo \\ Oslo, Norway
}

\begin{abstract}
The anabolic growth of dot.com-with third-generation network license auctions as the grand finale-implied a series of large investments in mobile technology. Without new products and services utilizing this infrastructure (m-services), however, these investments may never be recouped, and today there is no sure sign of demand for these new nomadic applications in the market. This paper shows how actors in the m-services value network coordinate their efforts to bring such applications to the marketplace. It shows their risk averse and locally optimizing strategies, which theoretically are very different from the current fascination in Information Systems with disruptive innovation. This paper illustrates the need for a theory of ordinary innovation in nomadic and ubiquitous computing.
\end{abstract}

\section{INTRODUCTION}

The adoption of mobile services seems to be fading in the Scandinavian countries. This is not due to a lack of interest in mobile devices, however. Although some markets are almost completely saturated with respect to mobile phones ( 96 percent ownership in Norway ${ }^{1}$, there is still growth in hardware sales. For example, Norway and Sweden, currently among the most mature markets in this respect, saw a 25 percent increase in sales last year alone.

${ }^{1}$ First half of the year 2004, as reported by the Norwegian Postal and Telecommunication Authority. 
Network traffic is also increasing, with Sweden, Norway, and Denmark showing a 10 to 20 percent growth in mobile-originated voice traffic time. However, the operators' revenue in Sweden decreased by 2 percent, ${ }^{2}$ probably due to increased competition. According to analysts, new services will be required in order to secure growth and justify investments in next-generation mobile telephony ${ }^{3}$ (Vincent 2001).

Next-generation mobile telephony is very much a product of the expansive business conjunctures toward the end of the 1990s. ${ }^{4}$ This period was characterized by its orientation toward radical innovation and technologies (typically Internet-based), which would (it was claimed) radically change the industrial landscape which they entered. ${ }^{5}$ For instance, one of the companies which we are currently studying was at one point devoted to developing "a revolutionary system that provides the user with easily understandable travel assistance before and during a journey." Its ambitions included

- $\quad$ Stunning use of $2 \mathrm{D}$ and $3 \mathrm{D}$

- Cutting-edge technology and methodology

- Unique visualization

- Multi-resolution image representation

This type of rhetoric was not conflated by the burst of the dot.com bubble, however. The aim of most projects back then was to create radically new functionality on top of an infrastructure (the Internet) that had taken on almost mythological proportions, and of which it was though no one could really envisage its limitations. This line of attack it seems, has become reified as the definition of innovation as such. Indeed, many programs offering innovation studies and training in entrepreneurship are preoccupied with the idea of a start-up, unique ideas, and the hard work of a dedicated, enthusiastic team. ${ }^{6}$

Within academia as well, and perhaps most coherently building on the framework of disruptive innovation as proposed by Christensen (1997), there has been lot of interest for this category of innovative processes. In this perspective, disruptive technologies are described as creating entirely new markets through new technology. This technology might initially be underperforming compared to sustaining technologies which are meeting the needs of the biggest, most profitable customers. However, it serves the need of a fringe segment of customers who would otherwise not be able to enjoy this functionality (it might, for example, simply be cheaper or offer less mainstream, but still critical functionality for some). When technology development catches up with customer requirements (and, simplistically, Moore's law implicates that it will), then it is too late for the incumbent to become competitive: The industrial landscape has changed.

${ }^{2}$ See http://www.digi.no/php/art.php?id=114473.

${ }^{3}$ See http://www.digi.no/php/art.php?id=113043.

${ }^{4} \mathrm{See}$ http://wirelessreview.com/mag/wireless grief dotcom era/.

${ }^{5}$ Insofar as we know, there have not been any systematic studies of the dot.com rhetoric as such. However, many good examples exist (see http://www.funkybusiness.com/funky/).

${ }^{6} \mathrm{See}$ http://www.grunderskolen.no, for example, or http://www.hbs.edu/entrepreneurship/ bplan/findteam.html, where the business plan contest is a particularly good illustration. 
In some of this literature, not only does it become apparent that disruptive innovation is a laudable objective, inasmuch as the alternative outcome is extinction (Christensen 1997), but it is also one for which normative or at least methodological steps can be taken (Christensen and Overdorf 2000; Cosier and Hughes 2001; Kostoff et al. 2004; Thomond et al. 2003).

Although we are not, in this paper, going to argue strongly against the perspective outlined above, we wish to present an empirical framework that as a supplement can help us better understand, on a more detailed level, the transformations in the telecommunications market as they unfold over time as well as on a day-to-day basis.

Currently, mobile services show modest uptake and high price sensitivity. However, such services are embedded in a complex and not completely open infrastructure; there is fundamentally a high threshold for content providers wanting to come out into the marketplace with new services. They need access agreements with operators. They need a mechanism for billing, and the medium itself is not used widely enough for it to be useful as a marketing platform; content providers have to market their products in other (and more expensive) channels such as magazines in order for consumers to become aware of the services. Additionally, consumers are still quite demanding and competition is tough. For service providers and developers, therefore, the risk is high. This is a situation in which actors have to coordinate their work finely and with a perspective of reducing risk, or they might end up in bankruptcy.

One of the biggest challenges in this emerging industry is to develop efficient and reasonable value chains. Making and managing value chains can be seen as coordinating business models and practices. Therefore, this paper will explore the ways in which coordination, which we find of primary importance, takes place between actors in the mobile service network in Norway. Three case studies, representing a content provider, a content aggregator, and the network operators, will be presented and discussed.

The next section of this paper will briefly discuss existing theories used in the mobile telecommunications arena. This will be followed by an overview of the three cases. The results of the case studies will then be presented through the discussion followed by the conclusion.

\section{RELATED RESEARCH}

There have been a number of studies carried out on $m$-business from various perspectives over the last several years. Telecommunications was (and is) an integral component of the promise of exponential growth of industrial activity and wealth that was made by the "new economy." Clearly, these promises were overly optimistic, but even though developments in this sector have fallen somewhat short of expectations, we are still witnessing a tremendous technological advancement in wireless networks and mobile technologies. Thus, this area has generated renewed interest in the research field.

Some of this recent research is oriented toward analyzing industrial developments in the telecommunications industry and the emerging business relationships on a macrolevel. For example, Lyytinen and King (2002) describe an innovation framework for the wireless industry. Their model of the innovation system, the market, and the regulatory 
regime has been adopted in studies of the mobile arena in different regions (see Yang et al. 2003; Fomin et al. 2004). Although this model is useful in pointing to essential interactions and relationships, in our cases we found an opportunity of delving into the same aspects on a more detailed, observable level.

Other work has been carried out within the same general tradition, but at a lower level of detail. For instance, Camponovo and Pigneur (2002) and Mylonopoulos et al. et al. (2002) focus specifically on an exploration of the various actors involved in the $\mathrm{m}$ business arena to provide insight into changing roles and relationships in this market. While work such as this has been useful to provide general guidance to the structure and composition of the mobile services arena, most contributions are primarily conceptual, rather than empirical. We believe that empirical contributions are warranted as well, and that they are indeed a necessary prelude to developing a coherent theory of this emerging domain.

\section{MOBILE SERVICES IN NORWAY}

We now turn to our cases: The Norwegian mobile network operators' (NetCom and Telenor) CPA (content provider access) platform, MultimediaContent.com's ${ }^{7}$ mobile content distribution, and $m P$ ay's mobile payment solution. Briefly, the CPA is a set of services that gives content providers access to the $\mathrm{SMSC}^{8}$-based infrastructure of the telecommunications network, as well as the billing services that make it possible (in a cost-effectiveness perspective, at least) to charge users for low-cost services. MultimediaContent.com is a content aggregator. Primarily, the services that they provide are

- managing suites of content (games, ring tones, logos) for mobile portals

- marketing to end-users as well as operators

- testing content for various handsets

$\mathrm{mPay}$ is both a content provider and a payment solution, providing a content service allowing users to pay for parking using their mobile phones and (in the future) a mobile payment solution service to content owners/aggregators. A simple view of our cases, then, is that they include a content provider (mPay), a content aggregator (MultimediaContent.com), and the operators (Telenor and NetCom).

Data was collected from our cases through a variety of qualitative methods. Related to the implementation and operation of CPA, a total of 39 formal interviews were conducted with managers, designers, and system developers in a total of 23 different organizations. Interviews were recorded and fully transcribed and included the network operators as well as the largest aggregators and content providers. The field site selected was thus not one organization, but rather a business sector with a range of actors which together provide the necessary resources, competencies and components to make up the

${ }^{7}$ Names have been changed for anonymity.

${ }^{8}$ Short message service center. 
platform. For the mPay case, several in-depth interviews were conducted with the founder and an employee in the organization. These were recorded and partially transcribed. Other informal discussions also took place and the data presented in this paper related to this case was reviewed and confirmed by the founder of the organization. For MultimediaContent.com, data was collected in semi-structured interviews with three managers, plus document studies facilitated by a project database covering the period from 1999 up to present activities.

The technical infrastructure upon which this value chain is configured is SMSbased. Customers request content using SMS, and receive (to their handset) a SMS or a push-WAP message. The handset deals with the message either by displaying content directly, or fetching it across GPRS from a URL embedded in the message. The crux of the wider business infrastructure will have to be found at the interplay and coordination of and between such actors, and we will present that next.

\subsection{The CPA Platform}

In 1997, the two Norwegian mobile phone network operators (NetCom and Telenor) launched platforms for exclusive content and utility-based SMS services for their respective mobile subscribers. Both attempts, however, suffered from only being a part of a "value adding services" offering and thus receiving limited internal resources either for investments in technology or investing in content. While these platforms generated very limited traffic, the network operators came to understand that external third parties, had the initiative, time, and resources to develop new service concepts. In addition, they appeared to be better equipped to know which services would be accepted by the market; how to market and price them correctly; and able to associate their brand with a wider variety of services than the network operators. Actors such as media windows, including newspapers, magazines, and TV broadcasters, also demonstrated their ability to provide relatively inexpensive marketing space for their own SMS services. At the same time, these external actors were pushing for market-wide access to subscribers.

To meet this situation, the mobile phone network operators launched the public content provider access (CPA) platform in 1999. While internal initiatives were taken by the network operators, proactive external actors played an important role in pushing the operators to introduce the platform. Their role in propelling the development of the platform has continued with application houses bringing together the network operators to develop service concepts such as interactive TV shows. The CPA platform enables external content providers to provide SMS services in a transparent manner, and charge subscribers for those services through the basic SMS structure (currently $0.15 €$ to $8 €$ ). Thus, the operators did not choose to compete on differentiation of services exclusively provided in one of the networks (as they previously had), but, on the contrary, pursued an "open garden" approach to increase the size of the total market. The typical content provided over the CPA platform comprises yellow pages, ring tones and logos, TV interactivity (voting and chat), games, news, stock quotes, weather information, traffic information, horoscopes, jokes, etc. Today, this is the basis for an economically sustainable business with a total annual turnover of approx 1 billion NOK (125 million $€)$ in 2004 , a substantial growth from 600 million NOK in 2003. 
Content acquisition is initiated by subscribers requesting content by sending an SMS (short message service) to certain short numbers (e.g., 1999). The SMS is processed by the message center (SMSC) of the network operator and forwarded to the respective content provider by the CPA platform. Content providers have agreements (with similar request numbers and rating classes) with both network operators, making the platforms and the network operators transparent for the subscribers. The content provider returns the content to the subscriber via the CPA platform, and the cost which the subscriber is to be charged (on the regular phone bill) is specified with a rating class. Based on this, a billing request is sent by the CPA platform to the billing system of the respective operator. The revenue generated is basically shared between the network operator and the content provider as per an agreed (and standardized) revenue-sharing model (respectively 30/70).

The technical implementations of the CPA platforms by the network operators have been simple (both implementations were originally based on the previous platforms with additional open interfaces), at least partly as a result of these services still being considered value adding. At the same time, because of the network operators' legacies of message centers and billing systems in addition to the competition among them, close coordination such as standardizing the CPA interfaces for content providers have not been feasible. These different interfaces are creating a higher entry cost for new content providers; however, both integrators and aggregators provide support. While the integrators provide applications that deliver one common interface for the platforms, the aggregators further provide access to a short number and handle the administrative interaction with the network operators.

In Table 1, a comprehensive picture of the value chain is drawn with roles and tasks. While the different roles appear as independent, several actors may play several roles. For example, large aggregators collecting content from several content producers as well as content providers commonly also act as content providers, application houses and integrators. Some media windows, such as media houses and TV broadcasters, typically capitalize on their content as well as their media window for marketing purposes.

Table 1. Roles and Tasks Within CPA

\begin{tabular}{|l|l|}
\hline \multicolumn{1}{|c|}{ Roles } & \multicolumn{1}{c|}{ Tasks } \\
\hline Content producer & Content production \\
\hline Content provider & Content production, service innovation \\
\hline Aggregator & Service innovation, content aggregation \\
\hline Application house & Service innovation \\
\hline Integrator & Providing common interfaces to CPA platforms \\
\hline Network operator & Transportation, billing \\
\hline Media window & Marketing \\
\hline Subscriber & Consume content services \\
\hline
\end{tabular}


Guidelines related to the services that can be provided, how they are marketed, and how the subscribers are treated have been important for avoiding behavior that may jeopardize the market created by the CPA platform. However, coordinated guidelines were not formalized and introduced until late 2004 (based on regulations and discussions with the Norwegian Competition Authority, the Consumer Ombudsman, and the Data Inspectorate). Up until then, the majority of content providers were cautious not to bring the platform too much attention from the media and the authorities. Provision of content services for fixed line phones in Norway are strictly regulated when it comes to content, for pricing as well as revenue sharing models. The risk of the introduction of a similar regulations for the CPA platform made content providers and network operators even more eager to avoid misuse and media attention.

The network operators' delegation of the responsibility of developing new service concepts and bringing them to the market to external actors has been successful in the sense of increased traffic and a much broader service offering. The CPA platform is not a detached platform provided by a network operator, but appears more like an assemblage of a range of different actors with their respective initiatives, investments, and technical components. On the one hand, the network operators have arranged a highly favorable revenue sharing model while still being in control of the value chain. At the same time, they are farming out the responsibility for further technical development to actors such as application houses, leaving them with marginal expenses. On the other hand, many smaller actors take responsibility for developing new services and service concepts. They receive limited revenues as, in the worst case, they must share with several other actors (content producers, content providers, aggregators, application houses, integrators, and media windows). Primarily having only a handful of employees, they are also usually opportunity-based in the sense that they are narrowly focused on developing trendy services and selling for the moment. They are thus neither very well equipped and nor primarily focused on introducing new service concepts. As long as CPA is the only alternative for providing this type of content services, the services will have to conform to its business model and the kind of services it supports.

\subsection{Mobile Content Distribution}

Multimedia.com is an independent provider of mobile games and marketing applications. They started out in 1993 as a small start-up with grand ambitions and only two owners, both of whom were employees. Today the company has around 120 shareholders. Early in the $1990 \mathrm{~s}$, the focus was on Internet technology, games, and direct (demographically based) marketing and animation. Eventually Multimedia.com turned toward the mobile market in 1998-1999 and started working on algorithms that made 3D-animation on mobile phones possible via very limited bandwidth. This culminated in several successful demonstrations in collaboration with Ericsson (at industry shows such as Telecom 1999, CeBit 2000, GSM 2000).

Unfortunately, the market for such applications nevex really came about, and the company has been struggling since 2000 with finding a value proposition that customers (mainly operators) would find attractive. They have ended up producing and deploying consumer-oriented content to mobile phones: logos, ring tones, and games. This activity mainly takes place in the subsidiary MultimediaContent.com Ltd, which has 
distribution agreements with several operators and "storefronts" on the Web worldwide. Over 100 content providers have entered into signed agreements with MultimediaContent.com and they have also signed an exclusive 5 year commercial agreement with one of the larger divisions of a Chinese operator to provide premium SMS and data services. MultimediaContent.com has developed a technology-independent platform for mobile content management, provisioning, and distribution, based on experiences from another subsidiary of Multimedia.com, DigitalMobility.com.

Distributing content to mobile terminals is based on SMS and WAP. SMS is the carrier for requests. WAP is the application protocol. The application server (which is, for all practical purposes, a virtual machine that makes its applications available on the Internet via an interface that wraps simple data types in XML) creates on request (received via an SMS gateway, for instance) a push access protocol (PAP) message which is then sent to the WAP push-enabled mobile telephone across SMS. The technical coordination, thus, is quite simple: The users send an SMS to the operator with the name of the item they want. The operator's CPA platform (or equivalent) recognizes the number, associates that with a content provider, and queries their MultimediaContent.com platform (or equivalent) for the URL for that particular item. The application server gets the URL and produces a PAP which it sends to the push proxy/mobile gateway. From there it goes to the user's phone, which fetches the content using WAP with SMS or GPRS as a bearer.

The technology involved is really simple, but the business is risky. No one knows in advance exactly which applications (ring tones, games, logos, etc.) will bring in enough money to defend development costs (and recover sunk costs for failed attempts). When the first-movers successfully established themselves in this business, the costs of development were lower; there was less competition and the consumers were not so demanding. Now, one must look at the coordination between actors in this setting from different angles, for example, as parts of a political and tactical positioning toward a more mature market. The parties need to do practical knowledge management since they are not at all self-contained with regards to the competencies required to implement an end-to-end service. They need to implement risk management (and risk sharing) strategies, since succeeding with a end-to-end service requires a much greater investment than what each party could afford individually (given that they do not know in advance what exactly will become a "hit" in the market). Therefore, coordination in the commercial aspects of this case is a lot more involved. It does the work of orchestrating many small contributions into a larger offering that the market, in total, just might end up paying enough to justify the expense. The roles of the various actors involved and their tasks are summarized in Table 2.

The roles presented in Table 2 overlap nicely with the requirements of consumer content for the impulsive, highly mobile customer: The storefronts market content by building a strong brand name; they subscribe to content from aggregators who take the responsibility of testing the content for all the handsets supported by an operator in an area. Developers need aggregators in order to handle internationalization and testing for them. Operators are "bit-pipe-carriers," plus they can do the billing effectively. Web hotels have an established role. It is probably not critical, but since most of these actors are small (typically 2 to 20 employees, which is already more than they can defend in terms of cash-flow), they would probably not be willing to try to handle hosting themselves for such small volumes of traffic. 
Table 2. Roles and Tasks in Mobile Content Provisioning

\begin{tabular}{|l|l|}
\hline \multicolumn{1}{|c|}{ Roles } & \multicolumn{1}{c|}{ Tasks } \\
\hline $\begin{array}{l}\text { Game } \\
\text { developer }\end{array}$ & $\begin{array}{l}\text { Conceptualizing, implementing and carrying out programming } \\
\text { projects which produce games, typically for the J2ME platform. }\end{array}$ \\
\hline $\begin{array}{l}\text { Content } \\
\text { provider }\end{array}$ & $\begin{array}{l}\text { Managing rights and technical adaptation of content for various } \\
\text { platforms, such as ring tones, logos, etc. }\end{array}$ \\
\hline Aggregator & $\begin{array}{l}\text { MultimediaContent.com's role. The most important task is to } \\
\text { compile a set of appealing services and introduce them to } \\
\text { storefronts, i.e., Web portals. They also test content for the } \\
\text { relevant mobile phones in the market. The aggregator pays the } \\
\text { developers. }\end{array}$ \\
\hline Storefront & $\begin{array}{l}\text { This is the media window that the consumer sees, e.g., on the } \\
\text { web, which brand and present a collection of content (from } \\
\text { various or only one aggregator) in their market. }\end{array}$ \\
\hline $\begin{array}{l}\text { Network } \\
\text { operator }\end{array}$ & $\begin{array}{l}\text { The owner of the technical infrastructure makes sure that there } \\
\text { is capacity and capabilities in the network to deal with the } \\
\text { requests and the traffic. Moreover, in the mobile telecommuni- } \\
\text { cations industry, this is the "owner" of the customer and, thus, } \\
\text { the role that can cost-effectively perform billing. }\end{array}$ \\
\hline Web hotel & $\begin{array}{l}\text { Stores the data. Any data. The telephone will fetch content } \\
\text { here given the URL received. }\end{array}$ \\
\hline
\end{tabular}

To summarize, Multimedia.com started out trying to invent and introduce revolutionary and disruptive technologies. However, they seem to have ended up in a more modest "Kirznerian" role of an entrepreneur that promotes equilibrium within the existing system as they "discover gaps, increase the knowledge about the situation and reduce the general level of uncertainty" (Hultén and Mölleryd 2000). Multimedia.com's subsidiary MultimediaContent.com makes it possible for small developers to take great risks by introducing their content together with a critical mass of others into a market that has a limited albeit smoothly coordinated business model.

\section{3 mPay}

mPay is a mobile payment solution developed in 2001, owned by Scangit AS in Norway. Currently this organization offers primarily a parking payment service, and has service agreements with private and public parking organizations in Norway such as EuroPark, P-Compagniet, the city of Oslo, and other municipalities around the capital. The concept for this service is that customers are able to use their mobile phone in order to pay for or extend parking rather than using coins in the parking meter. The motivation for people to use the service is the convenience of not having to find coins and the ability to pay for the exact amount of parking used (no overpaying and no forgetting about the parking meter). While the mobile payment service is today offered only for 
parking, mPay hopes to expand their payment solution to other products and to other content providers in the future. Thus, mPay can be considered both a payment solution service and a content provider.

In order to use the mPay service, customers need to register via the Internet, entering their personal data including their credit card information for payment. This information is all stored by mPay. Once the customer is registered, they are able to use the service by sending an SMS message through their mobile phone. Payment for the services initiated by the customer is managed by $\mathrm{mPay}$ and performed in cooperation with major credit card banking institutions including Teller (formerly Visa Norway), Euroconex, and Nordea. Once the customer sends an SMS message to pay for the product (parking), the message is transferred through to $\mathrm{mPay}$, who matches the message with the registered customer information. This customer information, including the billing information, is then transferred to the banking institution on a regular basis for payment for the service. Thus, mPay is essentially a payment solution service that acts as an intermediary between the customers, (potentially) other content providers, and the banking institutions, carrying none of the risk associated with the transaction.

mPay originated through cooperation with EMT, Estonia and, as a content provider for parking services, currently has only one main competitor in Norway: EasyPark. EasyPark was established in 1998 and is the current leader for mobile parking payment in Norway with approximately 12,500 customers. Both mPay and EasyPark afford customers the ability to pay for parking services through various means, including via major credit cards, such as Visa or MasterCard. While mobile payment for content via credit cards is not a unique situation in Norway and other services exist which also provide such capabilities, the mPay model is of interest as it offers the ability to establish payment for content via a channel not necessarily under the control of the network operators, as is the case for most services and models currently available in Norway. One of the few exceptions is the "electronic wallet" type of service such as Payex, which resembles the mPay model as it provides customers a payment option other than one closely associated with the mobile network operators. The main difference is that Payex primarily requires consumers to "fill up" their account prior to being able to purchase content whereas mPay debits or charges purchases directly to the credit or debit card as content is purchased.

As a payment solution service, $\mathrm{mPay}$ has become another actor in the overall $\mathrm{m}$ services value chain and hopes to offer a new alternative to content providers often frustrated with the CPA model described above. However, as a new actor, the roles and responsibilities of the various players in the value chain have shifted slightly where some tasks previously managed by the mobile operators, such as managing customer information or billing, are now managed by mPay (see Table 3). Just as in the CPA case, actors in this value chain may play several roles. For example, with mPay providing payment for parking services, it is playing the role of a content provider as well as payment intermediary.

Once the consumer is registered for the mPay service, mPay manages this customer information and the billing for content consumed. Actual billing for this content is handled through regular Visa, MasterCard, etc. bills by the respective banking institutions as described above. Thus, one of the major changes in the mPay model versus the CPA model is the control of customer information and billing. In addition, because mPay essentially manages contact between customers, parking institutions 
Table 3. Roles and Tasks in mPay

\begin{tabular}{|l|l|}
\hline \multicolumn{1}{|c|}{ Roles } & \multicolumn{1}{c|}{ Tasks } \\
\hline Network operator & Provide infrastructure and network \\
\hline Content owner & Own content, agree content availability to market \\
\hline Content provider & $\begin{array}{l}\text { Provide content services to market, manage agreements with } \\
\text { content owners }\end{array}$ \\
\hline mPay & $\begin{array}{l}\text { Manage billing for content consumed; manage agreements } \\
\text { with content providers and banking institutions. Manage all } \\
\text { customer information }\end{array}$ \\
\hline $\begin{array}{l}\text { Banking } \\
\text { institutions }\end{array}$ & Provide billing for content consumed, manage payments \\
\hline Consumer & Consume content services, register as mPay customer \\
\hline
\end{tabular}

(content owners) and banking institutions, the key to the mPay service model rests primarily on coordination and agreements, many of which were established and are managed through informal networks by the founder of the service. These informal channels have been a key to the initiation of the mPay service and its original success in the market

\section{DISCUSSION}

We can now explore the activities and the interdependencies between the cases while also investigating possible simultaneity constraints and eventual outsourcing of responsibilities and work. This will, of course, be greatly simplified but perhaps it can point in the direction of general trends in this market or to areas in which a future theoretical framework could be used.

In each of the cases, the activities and goals of the actors converge at a general level and can be discussed in relation to the coordination of processes surrounding content acquisition and distribution. For example, in establishing the CPA model, the primary goal for the network operators seems to have been to provide a channel for content owners to sell and distribute content (and thus generate network traffic) without giving up control of the physical infrastructure or the customer relationships they currently have. Thus, the CPA model is a win-win for the network operators as it requires little effort on their part while they gain revenue in the form of revenue sharing from content sold, increased network traffic, and increased potential customer support. The mPay model, on the other hand, can be viewed as one competing solution to this CPA model as $\mathrm{mPay}$ hopes to establish a relationship with customers themselves and to manage billing information, etc. such that they can offer content providers another option for the billing of content. Finally, MultimediaContent.com is essentially a content aggregator with the objective of compiling a sufficiently interesting set of services into one packaged offering, and then make a profit from brokering these services. 
Coordination of these activities takes place through standardized agreements and interfaces: The CPA is a "one-size-fits-all" contract with entrance costs that also serve as a threshold for small, independent content providers. Instead, operators want aggregators to deal with the content providers. The operators channel traffic through to the storefronts, which return input and the price to be charged, and accordingly initialize billing. Apart from that, operators (automatically) generate SMS and WAP pushmessages through their infrastructure and all they see are SMS messages and URLs. Aggregators make sure that the content is tested and they take money from the storefronts, which they split between themselves and the content providers. Again, this is regulated by a standardized contract (in the MultimediaContent.com case). Similarly, mPay mediates a standard contract between the customer and the banking institution. Basically, they are virtual machines that imprint the voucher and send an electronic copy to the credit card company.

Looking at these three cases together, it becomes clear that a lot of the coordination work that is carried out aims at reducing risk and minimizing variable expenses for each of the actors. For example, mPay's role as an intermediary allows them to offer content without carrying any risk associated with the transaction, leaving this responsibility to the banking institutions. Similarly, the CPA model essentially alleviates the operators from any risk associated with unfavorable or illegal content by positioning this task with the content aggregators. At a general level, this is a strategy of optimizing locally, and it is not really representative of tremendously innovative or distuptive technologies. This is perhaps the single most interesting point that can be identified from our fieldwork: There are no disruptive technologies at play, and this is certainly something worth looking more keenly at in future research. For instance, Multimedia.com, as a typical dot.com company with highly disruptive ambition ended up (finally) being successful at making a modest profit from locally optimizing one existing step of the value network in telecom, rather than revolutionizing it.

What, then, is the effect of this local optimization? We think that the question should be turned around: What is the reason that we see such local (rather than systemic) optimization? Given that most of the current services offered today are rather lightweight and carefree entertainment services, which are bought by the customer in a spur-of-the-moment impulsive transaction, the cost of building, marketing, and billing is rather out of proportion with the actual price that one can expect the user to be willing to pay. Building an innovation infrastructure on top of which new businesses and truly innovative application ideas can be deployed is a tremendous challenge, which we will continue to address in our research. And while the network operators have created new business for content providers by implementing CPA platforms according to a open garden philosophy, the platforms implemented are only minor extensions of their existing infrastructure and the network operators' control over the value chain is far from being challenged and deconstructed into a value network.

Within these cases, the interdependencies are evident, much of it related to the outsourcing of various tasks and processes. For example, MultimediaContent.com outsources the hosting of content, either back to the storefront or to a Web hotel. This is not an ideological choice; instead, it is rather pragmatic. The mother company has a lot of competencies in this area but they are all located abroad, in a country with is limited and unreliable Internet capacity. Perhaps the most important resource in the emerging market of mobile services is the presentation of services in the context of 
marketing. In order for customers to impulsively buy indifferent content, such as ring tones, logos, and games, the marketing has to be aggressive and strong. Therefore, such a simple resource as the common short number (e.g., 1999) for services across operators is a valuable resource. For the content providers, access to the validated customer database and the factoring services of the operators or credit card companies is a valuable resource. The CPA provides the necessary mechanism for preparing and pushing the WAP messages with content or URLs to the handsets.

Coordination in this emerging industry seems to be mainly about managing loose interdependencies in a nonlinear value chain of actors. They are not concerned with traditional manufacturing challenges of optimizing their production lines, or even working together toward a common goal. Nor are they (as in the alternative dot.comconception of the telecommunication industry) concerned with crafting an entirely new economy that will revolutionize large parts of society. The reality seems to be rather in the middle. Actors coordinate their efforts so that they can hedge their value propositions by creating critical mass and sharing risk related to development and marketing. Thus, they can secure a minimal cash-flow and, simply, keep going.

\section{CONCLUSION}

Over the past decade, we have seen tremendous growth in the telecommunications sector. However, growth has not been uniform. Vendors still see increasing sales of new devices. A lot of it is marketed by promises made about appealing new services that will be made possible by the next-generation technology. These promises, however, remain primarily unfulfilled. Starting to uncover why this is the case and putting ourselves in a position from which remedies may be proposed, we have analyzed one excerpt from the value chain of this industry. Although, at this stage, chiefly descriptive in nature, our research aims to create a constructive intellectual platform.

Our ambition is to move on with more in-depth studies of this field. It should be guided by a clearly defined knowledge interest, which in part has been inspired by the findings of this paper: Why do actors only successfully engage in limited exploitation of next-generation nomadic computing? Why are there such a limited number of new applications being developed and, to the extent that they are, why is the end-user adoption so modest? The contribution and development of theoretical frameworks play an important part in understanding this picture. Good analytical mechanisms may help us understand how the field is unfolding; they provide useful concepts and predict change. However, empirical studies such as those presented in this paper are a necessary platform for such work in the next instance.

\section{REFERENCES}

Camponovo, G., and Pigneur, Y. "Analyzing the Actor Game in m-Business," in Proceedings of the First International Conference on Mobile Business, N. A. Mylonopoulos (Ed.), Athens, Greece, 2002 (available online at http://www.mobiforum.org/proceedings/papers/ 01/1.1.pdf. 
Christensen, C. M. The Innovator's Dilemma: When New Technologies Cause Great Firms to Fail, Boston: Harvard Business School Press, 1997.

Christensen, C. M., and Overdorf, M. "Meeting the Challenge of Disruptive Change," Harvard Business Review, March-April 2000, pp. 67-76.

Cosier, G., and Hughes, P. M. "The Problem with Disruption," BT Technology Journal (19:4), October 2001, pp. 9-14.

Fomin, V. V., Gao, P., and Damsgaard, J. "The Role of Standards and its Impact on the Diffusion of 3G Wireless Mobile Services," in Proceedings of the European Academy for Standardization: $9^{\text {th }}$ EURAS Workshop on Standardization, F. Bousquet, Y. Buntzly, H. Coenen, and K. Jakobs (Eds.), Paris, May 13-14, 2004, pp. 97-104.

Hultén, S., and Mölleryd, B. "Entrepreneurs, Innovations and Market Processes in the Evolution of the Swedish Mobile Telecommunications Industry," paper presented at the Eighth International Joseph A. Schumpeter Society Conference, Manchester, UK, June 28-July 1, 2000.

Kostoff, R. N., Boylan, R., and Simons, G. R. "Disruptive Technology Roadmaps," Technological Forecasting and Social Change (71), 2004, pp. 141-159.

Lyytinen, K., and King, J. L. "Around the Cradle of the Wireless Revolution: The Emergence and Evolution of Cellular Telephony," Telecommunications Policy (26:2), 2002, pp. 97-100.

Mylonopoulos, N., Sideris, I., Fouskas, K., and Pateli, A. "Emerging Market Dynamics in the Mobile Services Industry," White Paper WHP-2002-01, MobiCom Consortium, 2002 (available online at http://www.mobiforum.org/cgi-bin/mobi/mobi.cgi).

Thomond, P., Herzberg, T., and Lettice, F. "Disnuptive Innovation: Removing the Innovators' Dilemma. Knowledge," paper presented at the British Academy of Management Annual Conference, Harrogate, UK, September 2003.

Yang, H., Yoo, Y., Lyytinen, K., and Ahn, J-H. "Diffusion of Broadband Mobile Services in Korea: The Role of Standards and its Impact on Diffusion of Complex Technology System," paper presented at the Workshop on Ubiquitous Computing Environment, Cleveland, Ohio, October 24-26, 2003.

Vincent, G. "Learning from i-Mode," IEEE Review (47:6), 2001, pp. 13-18.

\section{ABOUT THE AUTHORS}

Steinar Kristoffersen is a post-doctoral research fellow with the Department of Informatics at the University of Oslo, holding a Ph.D. from Lancaster University, UK. He worked as a consultant in mobile applications development for 5 years before returning to do academic research. Before that, he was a research director at the Norwegian Computing Centre. His current areas of research include infrastructures, innovation and methods; architectures for mobile IT, computer-supported cooperative work ( $\mathrm{CSCW})$, and human-computer interaction (HCI). Steinar can be reached at steinkri@ifi.uio.no.

Petter Nielsen is a Ph.D. candidate at the Department of Informatics at the University of Oslo. His research interests are related to strategies for designing services for mobile devices. He is currently engaged in empirical research related to the emergence of new content services and telecommunication platforms, seen as a result of convergence between telecommunication and information technology, both locally and on a global scale. Petter can be reached at pnielsen@ifi.uio.no.

Jennifer Blechar holds an MSc in Analysis, Design and Management of Information Systems from the London School of Economics and Political Science, UK, and a BA in Mathematics from Bryn Mawr College, USA. She is currently a Ph.D. candidate and research fellow with the Department of Informatics at the University of Oslo, Norway, and has several 
years experience as a consultant within the telecommunications field. Her research interests involve the design, implementation and diffusion of high value content services in the mobile industry. Jennifer can be reached at jennifjb@ifi.uio.no.

Ole Hanseth (http://heim.ifi.uio.no/ oleha) is Professor at the Department of Informatics at the University of Oslo. He worked for a number of years within applied research and business until he moved back to academia in 1997. His main research interests are related to large scale information systems and infrastructures. Ole can be reached at oleha@ifi.uio.no. 